\title{
The Capacity to Secrete Insulin Is Dose-Dependent to Extremely High Glucose Concentrations: A Key Role for Adenylyl Cyclase
}

\author{
Katherine M. Gerber ${ }^{1,+}$, Nicholas B. Whitticar ${ }^{2,3,+}$, Daniel R. Rochester ${ }^{2}$, Kathryn L. Corbin ${ }^{2}$, William J. Koch ${ }^{2,3}$ \\ and Craig S. Nunemaker ${ }^{2,4, *}$ \\ 1 Translational Health, Honors Tutorial College, Ohio University, Athens, OH 45701, USA; kg010716@ohio.edu \\ 2 Biomedical Sciences, Heritage College of Osteopathic Medicine, Ohio University, Athens, OH 45701, USA; \\ nw575612@ohio.edu (N.B.W.); dr935216@ohio.edu (D.R.R.); corbink1@ohio.edu (K.L.C.); \\ wk922015@ohio.edu (W.J.K.) \\ 3 Translational Biomedical Sciences Program, Heritage College of Osteopathic Medicine, Ohio University, \\ Athens, OH 45701, USA \\ 4 Diabetes Institute, Heritage College of Osteopathic Medicine, Ohio University, Athens, OH 45701, USA \\ * Correspondence: nunemake@ohio.edu; Tel.: +740-593-2387 \\ + These authors contributed equally to this work.
}

\section{check for} updates

Citation: Gerber, K.M.; Whitticar, N.B.; Rochester, D.R.; Corbin, K.L.; Koch, W.J.; Nunemaker, C.S. The Capacity to Secrete Insulin Is Dose-Dependent to Extremely High Glucose Concentrations: A Key Role for Adenylyl Cyclase. Metabolites 2021, 11, 401. https://doi.org/ 10.3390/metabo11060401

Academic Editors: Belinda Yau and Melkam Kebede

Received: 31 May 2021

Accepted: 18 June 2021

Published: 19 June 2021

Publisher's Note: MDPI stays neutra with regard to jurisdictional claims in published maps and institutional affiliations.

Copyright: (c) 2021 by the authors. Licensee MDPI, Basel, Switzerland. This article is an open access article distributed under the terms and conditions of the Creative Commons Attribution (CC BY) license (https:/ / creativecommons.org/licenses/by/ $4.0 /)$.

\begin{abstract}
Insulin secretion is widely thought to be maximally stimulated in glucose concentrations of 16.7-to-30 mM (300-to-540 mg/dL). However, insulin secretion is seldom tested in hyperglycemia exceeding these levels despite the Guinness World Record being $147.6 \mathrm{mM}$ (2656 mg/dL). We investigated how islets respond to 1-h exposure to glucose approaching this record. Insulin secretion from human islets at $12 \mathrm{mM}$ glucose intervals dose-dependently increased until at least $72 \mathrm{mM}$ glucose. Murine islets in $84 \mathrm{mM}$ glucose secreted nearly double the insulin as in $24 \mathrm{mM}(p<0.001)$. Intracellular calcium was maximally stimulated in $24 \mathrm{mM}$ glucose despite a further doubling of insulin secretion in higher glucose, implying that insulin secretion above $24 \mathrm{mM}$ occurs through amplifying pathway(s). Increased osmolarity of 425-mOsm had no effect on insulin secretion (1-h exposure) or viability (48-h exposure) in murine islets. Murine islets in $24 \mathrm{mM}$ glucose treated with a glucokinase activator secreted as much insulin as islets in $84 \mathrm{mM}$ glucose, indicating that glycolytic capacity exists above $24 \mathrm{mM}$. Using an incretin mimetic and an adenylyl cyclase activator in $24 \mathrm{mM}$ glucose enhanced insulin secretion above that observed in $84 \mathrm{mM}$ glucose while adenylyl cyclase inhibitor reduced stimulatory effects. These results highlight the underestimated ability of islets to secrete insulin proportionally to extreme hyperglycemia through adenylyl cyclase activity.
\end{abstract}

Keywords: amplifying pathway; hyperglycemia; adenylyl cyclase; incretins; glucokinase; forskolin; cAMP; exenatide; diabetes; insulin; islets

\section{Introduction}

Pancreatic beta cells secrete insulin in response to glucose stimulation to maintain blood glucose levels within a relatively narrow range [1]. Insulin is required to transport glucose from the bloodstream to target tissues. High blood glucose levels in the body are caused by problems with insulin secretion, insulin action, or both. Extremely high levels of glucose lead to the presentation of ketoacidosis or hyperosmolar hyperglycemic nonketoic syndrome, which are key indicators of the metabolic disease diabetes [2]. Poor control of glucose regulation in this disease can bring potential stupor, coma, or death [3].

In humans, insulin secretion is typically stimulated by glucose concentrations ranging from 4.4 to $6.6 \mathrm{mM}(80-120 \mathrm{mg} / \mathrm{dL})[2,4]$. Moreover, it is generally accepted that the effective concentration of glucose for half of the maximal insulin secretion $\left(\mathrm{EC}_{50}\right)$ is approximately $5 \mathrm{mM}$. These $\mathrm{EC}_{50}$ estimations are based on dose-response curves with the highest stimulation typically being described at $16.7(300 \mathrm{mg} / \mathrm{dL})$ to $30 \mathrm{mM}(540 \mathrm{mg} / \mathrm{dL})$. However, close inspection of published glucose dose-response curves suggests that even 
though a classic sigmoid dose-response curve should flatten out, the curves typically show an increasing trend of higher insulin secretion near the maximal glucose level tested. This provokes the hypothesis that insulin secretion may be sensitive to a much wider range of glucose concentrations than commonly thought [5-9].

Interestingly, there are multiple case reports of individuals who have had blood glucose levels greater than $100 \mathrm{mM}(1800 \mathrm{mg} / \mathrm{dL})$ and survived $[2,4,10,11]$. This includes the world record blood glucose level of $147.6 \mathrm{mM}(2656 \mathrm{mg} / \mathrm{dL})$ which was set by a young boy when admitted to the hospital [11]. The pathways involving insulin secretion at extremely high glucose concentrations have not been examined to our knowledge.

Glucose is the primary stimulator of insulin release from pancreatic beta cells. The ability of glucose to elicit an increase in intracellular calcium leading to insulin secretion is known as the triggering pathway [12-14]. This pathway begins when glucose enters the beta cell through both the GLUT 1 and GLUT 3 glucose transporters in human islets and the GLUT 2 transporter in mouse islets $[13,14]$. Glucose is then phosphorylated by glucokinase and yields glucose-6-phosphate which travels through glycolysis to yield pyruvate and ATP. Glycolysis and downstream mitochondrial metabolism drive the ratio of ATP to ADP to rise, leading to the closure of $\mathrm{K}_{\mathrm{ATP}}$ channels. This closure activates the voltage-dependent calcium channels to allow the influx of calcium that constitutes the triggering pathway for insulin secretion.

In addition to the triggering pathway, many different intermediate metabolites of glucose and other cellular components are thought to participate in a series of events known as the amplification pathway(s) in which $\mathrm{K}_{\text {ATP }}$ channel closure is not the source of the increased insulin secretion. A review on this topic contained within this special issue describes this pathway as "the sequence of events that enables the secretory response to a nutrient secretagogue to exceed the secretory response of a purely depolarizing stimulus" [15]. Cyclic adenosine monophosphate (cAMP) is a powerful player in the amplification pathway-related insulin secretion. Glucose is a known factor leading to the upregulation of cAMP which is formed from ATP via adenylyl cyclases [16], although the exact mechanism of metabolism stimulated cAMP is unknown. Additionally, there is a glucose-linked amplification pathway that augments insulin secretion through adenylyl cyclase (AC) activation caused by incretin stimulation. Incretins are hormones secreted by endocrine cells in the small intestine after meal ingestion that lead to insulin secretion [12]. Gastric inhibitory polypeptide (GIP) and glucagon-like peptide-1 (GLP-1) are specific incretins that act on the beta cell. Incretins interact with G-protein-coupled receptors at the cell membrane and lead to an upregulation of cAMP $[17,18]$. The common theme is that cAMP is involved in the early steps leading to insulin secretion in these amplifying pathway(s).

In this study, we aim to determine the relationship between glucose stimulation and insulin secretion in a much higher glucose range than typically examined. We show that insulin secretion is maintained in response to extreme glucose, osmolarity does not affect insulin secretion or islet viability at extreme levels, and that intracellular calcium is maximized at $24 \mathrm{mM}$ glucose. We also sought to identity possible pathway(s) used in extreme glucose conditions and found that adenylyl cyclase plays an important role.

\section{Results}

\subsection{Insulin Secretion Is Maintained in Response to Extreme Glucose}

Identifying the maximal physiological response of biological systems often gives insight into function. We wanted to determine what happens to insulin secretion above the commonly accepted maximum concentration of glucose for stimulation. We thus examined insulin secretion from human and murine islets in conditions of extremely high glucose. Islets from human donors were placed in mannitol-balanced Krebs-Ring buffer (KRB) solutions containing glucose ranging from $0 \mathrm{mM}$ to $144 \mathrm{mM}$ for $1 \mathrm{~h}$. As shown in Figure $1 \mathrm{~A}$, insulin secretion from each of the four donors was normalized to their respective maximal value and averaged amongst donors (see Table 1 for donor information). From 0 to $24 \mathrm{mM}$, 
there was a significant upward trend (rho $=0.93, p<0.001$ ) and from $24-84 \mathrm{mM}$, there was still a positive correlation, though not as strong ( $(r h o=0.73, p<0.001)$. Insulin secretion from murine islets was also measured (Figure 1B). From 0-24 mM, there was a strong upward trend (rho $=0.75, p<0.001$ ), and from $24-84 \mathrm{mM}$, there was still a significant positive trend ( $\mathrm{rho}=0.63, p<0.001$ ). Overall, there was a positive correlation between insulin and glucose for $0-24 \mathrm{mM}$, as expected, but a similar relationship exists from $24 \mathrm{mM}$ glucose and beyond.

A

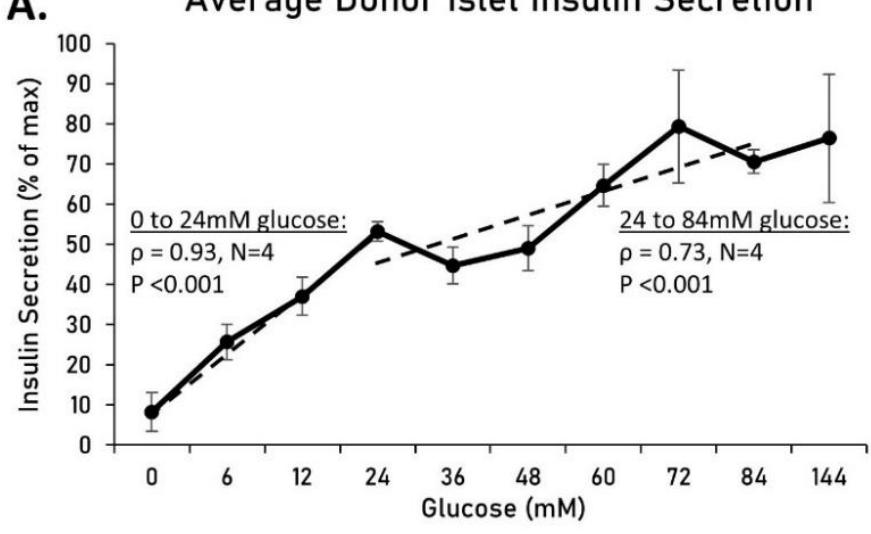

B. Average Murine Islet Insulin Secretion

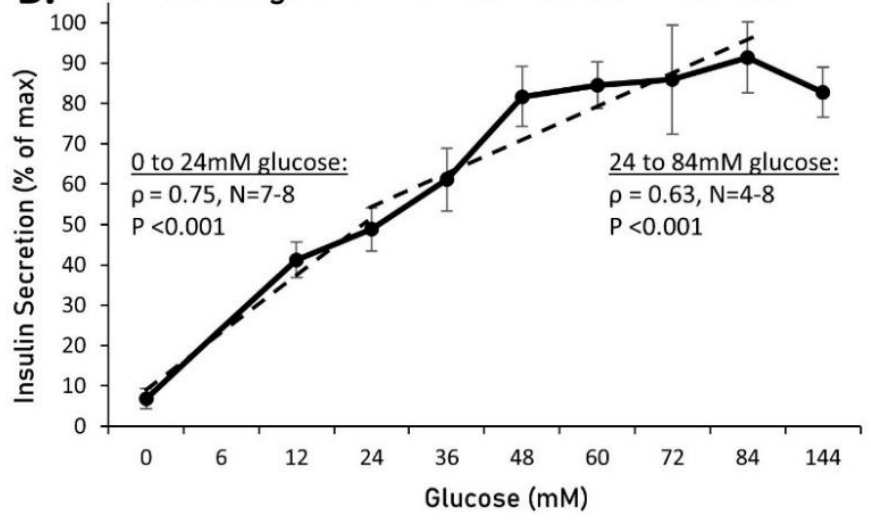

Figure 1. Human and murine islet insulin secretion in conditions of extremely high glucose. Islets from human donors (A) and mice (B) were placed in mannitol balanced KRB solutions containing glucose ranging from $0 \mathrm{mM}$ to $144 \mathrm{mM}$ for 1 h. Insulin secretion from each donor or mouse replicate was normalized to their respective maximal value and averaged. Dotted linear trendlines are drawn for 0-24 mM and 24-84 mM glucose to indicate slope, Spearman's rho, and the respective $p$-value.

Table 1. Human islet donor information.

\begin{tabular}{|c|c|c|c|c|c|c|c|c|c|c|c|}
\hline Source & Isolation ID & Purity & Donor Age & BMI & Height (m) & Weight (kg) & HbA1c & Sex & Diabetes & $\begin{array}{c}\text { Cold } \\
\text { Ischemia } \\
\text { Time (h) }\end{array}$ & $\begin{array}{c}\text { Donation } \\
\text { Type }\end{array}$ \\
\hline $\begin{array}{l}\text { IsletCore, } \\
\text { Univer- } \\
\text { sity of } \\
\text { Alberta }\end{array}$ & R286 & $95 \%$ & 41 & 20.4 & 1.80 & 66 & 5.2 & M & No & 13.5 & Neurological \\
\hline $\begin{array}{l}\text { IsletCore, } \\
\text { Univer- } \\
\text { sity of } \\
\text { Alberta }\end{array}$ & R318 & $90 \%$ & 54 & 20.5 & 1.85 & 70 & 5.0 & M & No & 16 & Neurological \\
\hline $\begin{array}{l}\text { IsletCore, } \\
\text { Univer- } \\
\text { sity of } \\
\text { Alberta }\end{array}$ & R322 & $90 \%$ & 44 & 23.2 & 1.58 & 58 & 4.9 & $\mathrm{~F}$ & No & 11.5 & Neurological \\
\hline $\begin{array}{l}\text { Clinical } \\
\text { Islet Lab, } \\
\text { Univer- } \\
\text { sity of } \\
\text { Alberta }\end{array}$ & H\#:2296 & $90 \%$ & 52 & 29.2 & 1.82 & 96.8 & 5.2 & $\mathrm{~F}$ & No & 4.5 & $\begin{array}{l}\text { Head trauma } \\
\text { (fall) }\end{array}$ \\
\hline
\end{tabular}

\subsection{Increased Osmolarity Does Not Alter Insulin Secretion or Islet Viability}

To control for osmolarity as a variable, solutions were balanced to $\sim 425 \mathrm{mOsm} / \mathrm{L}$ using the sugar alcohol mannitol. Mannitol was used to account for the difference in osmolarity between low and high glucose conditions, and here the effect of mannitol on its own was explored. Mannitol is not metabolized and therefore should not increase intracellular calcium or insulin secretion, although indirect factors such as membrane potential or ion flux might alter insulin secretion [19]. To investigate this possibility, islets were treated for $1 \mathrm{~h}$ in modified $\mathrm{KRB}$ with $0 \mathrm{mM}$ glucose or $84 \mathrm{mM}$ glucose with and without mannitol balanced to $144 \mathrm{mM}$. While it is known that various osmotic receptors 
on beta-cells have been shown to alter insulin secretion [20], as shown in Figure 2A, large increases in osmolarity caused no significant change in insulin secretion, and mannitol alone did not have a stimulatory effect. As expected, islets in each $84 \mathrm{mM}$ glucose group secreted significantly more insulin $(p<0.01)$ than islets in each glucose-free group, but osmolarity changes due to mannitol did not significantly affect insulin secretion.

A.

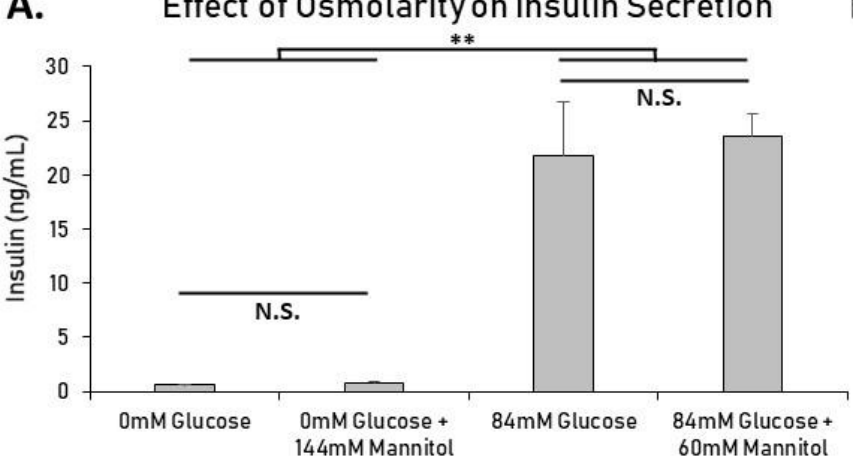

B.

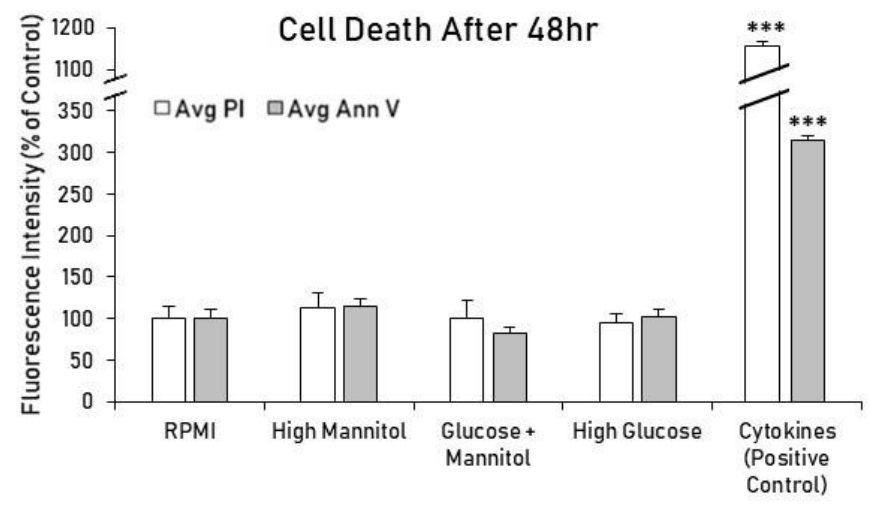

Figure 2. Effects of high glucose and mannitol on mouse islet insulin secretion and cell death. (A) Mouse islets were placed in wells containing modified $\mathrm{KRB}$ with $0 \mathrm{mM}$ or $84 \mathrm{mM}$ glucose \pm mannitol balanced to $144 \mathrm{mM}$ total for $1 \mathrm{~h}$. Increasing osmolarity using mannitol did not significantly alter insulin secretion in glucose-free or high-glucose solutions. Twenty islets per condition in duplicate ran in 2 separate trials $(\mathrm{N}=4)$. (B) Islets were placed in either standard RPMI, high glucose (144 mM), high mannitol (144 mM), or both glucose $(60 \mathrm{mM})$ and mannitol $(84 \mathrm{mM})$. Islets treated overnight with $5 \mathrm{ng} / \mathrm{mL}$ IL-1beta and $10 \mathrm{ng} / \mathrm{mL}$ TNF-alpha were used as a positive control to show typical fluorescence levels of induced cell death. Islets in each condition ranged from $\mathrm{N}=31-37$ after combining two separate trials. All data are presented as mean $\pm \mathrm{SEM}$. ${ }^{* *} p<0.01,{ }^{* * *} p<0.001$, N.S. $=$ Not Significant.

Next, we measured cell death using fluorescent microscopy to check for toxicity. Isolated mouse islets treated in standard RPMI, high glucose $(144 \mathrm{mM})$, high osmolarity $(144 \mathrm{mM})$, or a combination of both $(84 \mathrm{mM}$ glucose $+60 \mathrm{mM}$ mannitol) for $48 \mathrm{~h}$ displayed no significant differences in cell death (propidium iodide) or apoptosis (annexin V) (Figure 2B). Proinflammatory cytokines were used as a positive control to induce beta-cell death. Collectively, these results indicate that substantial increases in osmolarity have no effect on cellular function or viability in mouse islets in these conditions.

\subsection{Intracellular Calcium Is Maximally Stimulated in $24 \mathrm{mM}$ Glucose}

To determine whether these responses were calcium dependent, mouse islets were loaded with the calcium probe fura-2AM and exposed to increasing stimulation as indicated by the black bars in Figure 3. As expected, a large increase was observed in response to $24 \mathrm{mM}$ glucose stimulation. When the stimulus was increased from 24 to $84 \mathrm{mM}$ glucose, average calcium levels of all islets were not significantly different (Figure 3A). Large increases in glucose above $24 \mathrm{mM}$ do not appear to impact calcium handling. Furthermore, there was no significant difference between calcium levels in the $3 \mathrm{mM}$ and the $3 \mathrm{mM}$ wash $(p>0.05)$ showing that the extreme glucose did not alter the islet's ability to control the secretion process.

Tolbutamide, a sulfonylurea known to depolarize beta cells via reduction of potassium permeability, leads to the opening of voltage-dependent calcium channels to subsequently trigger insulin release [21]. As anticipated, there was no significant difference $(p>0.05)$ between $24 \mathrm{mM}$ and $24 \mathrm{mM}$ combined with $250 \mu \mathrm{M}$ tolbutamide in terms of intracellular calcium influx (Figure 3B). This supports the observation that intracellular calcium is maximally stimulated in $24 \mathrm{mM}$ glucose. 
A.

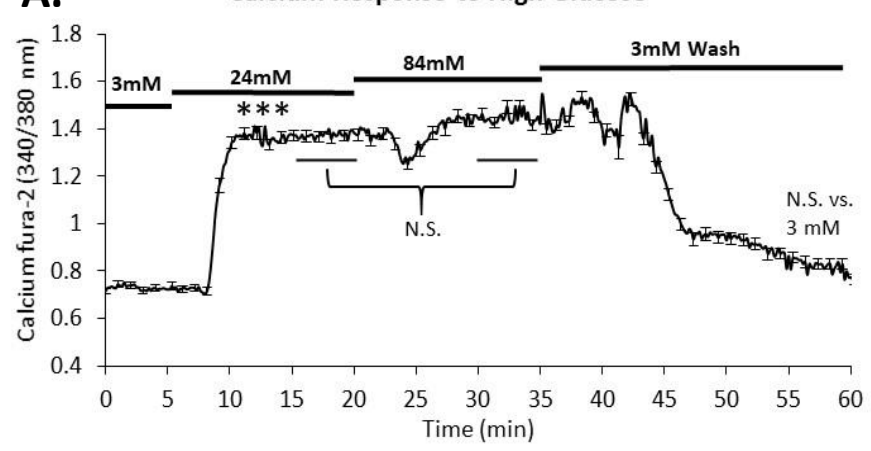

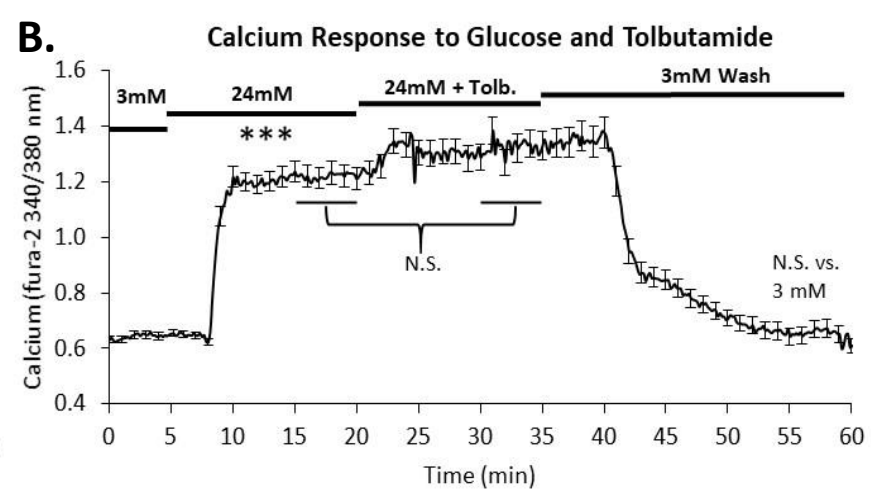

Figure 3. Effects of high glucose on intracellular calcium. (A) Intracellular calcium was measured in islets exposed to the increasing glucose conditions noted by the horizontal bars. Calcium levels increased sharply from $3 \mathrm{mM}$ to $24 \mathrm{mM}$ glucose but did not increase further when exposed to $84 \mathrm{mM}$ glucose. Average calcium levels from 23 islets were calculated from the 15-20- and 30-35 min time points and showed no significant difference. (B) Intracellular calcium was measured in islets exposed to the increasing glucose conditions and tolbutamide noted by the horizontal bars. Calcium levels increased sharply from $3 \mathrm{mM}$ to $24 \mathrm{mM}$ but did not increase further when exposed to $24 \mathrm{mM}$ glucose combined with $250 \mu \mathrm{M}$ tolbutamide. Average calcium levels from 23 islets were calculated from the 15-20 and 30-35 min time points and showed no significant difference. ${ }^{* * *} p<0.001$ difference between 3 and $24 \mathrm{mM}$ glucose.

\subsection{Glycolytic Capacity to Secrete Insulin Dose-Dependently Extends above $24 \mathrm{mM}$ Glucose}

We next conducted a series of trials to determine what drives increased insulin secretion in high glucose. The following studies were all conducted in $24 \mathrm{mM}$ glucose (regarded as maximal) and $84 \mathrm{mM}$ glucose (regarded as extreme). As shown in Figure $4 \mathrm{~A}$, insulin secretion was significantly higher in $84 \mathrm{mM}$ glucose compared to $24 \mathrm{mM}$ glucose after combining all trials $(p<0.001)$. The averages are reproduced for comparisons made in Figures $4 \mathrm{~B}$ and 5 .

A.

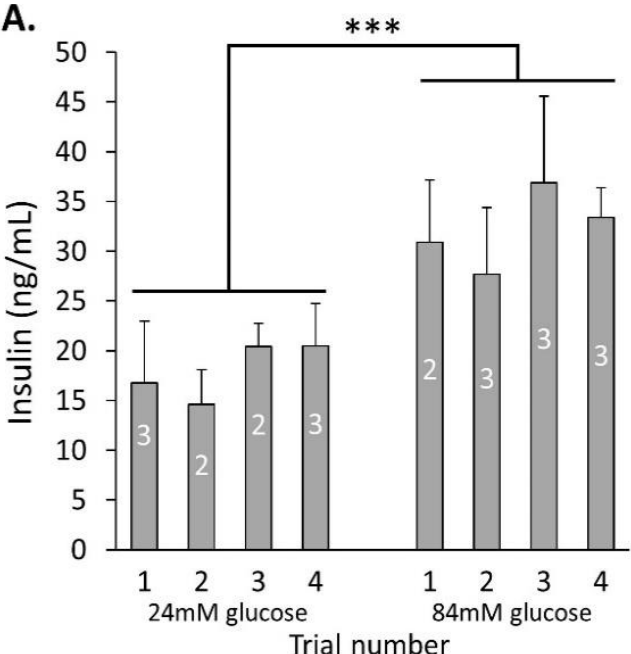

B.

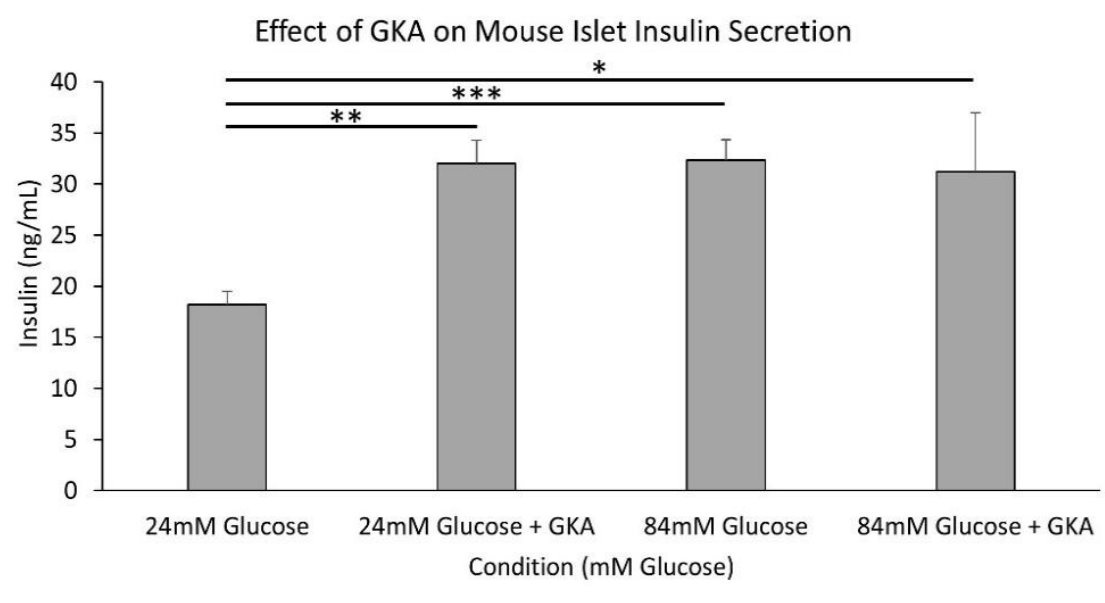

Figure 4. Insulin secretion in extremely high glucose is associated with increased glycolysis. (A) Insulin secretion was measured after $1 \mathrm{~h}$ incubation in $24 \mathrm{mM}$ glucose (regarded as maximal) and $84 \mathrm{mM}$ glucose (regarded as extreme) shown for four separate trials with $\mathrm{N}=2-3$ replicates to demonstrate consistency of the difference in insulin secretion from trial to trial. Combining these trials, the data were significantly different with a $p$-value of $<0.001$ by two-tailed T-test between 24 and $84 \mathrm{mM}$ glucose. (B) Mouse islets were placed in wells containing modified KRB with $24 \mathrm{mM}$ or $84 \mathrm{mM}$ glucose \pm mannitol balanced to $84 \mathrm{mM}$ total for $1 \mathrm{~h}$ with or without $500 \mathrm{nM} \mathrm{GKA}$. The GKA increased insulin secretion significantly in $24 \mathrm{mM}$ glucose $(p<0.01)$ but failed to do so in $84 \mathrm{mM}$ glucose. All data are presented as \pm SEM. $\mathrm{N}=3-11$ replicates. ${ }^{*} p<0.05$, ${ }^{* *} p<0.01,{ }^{* * *} p<0.001$. 

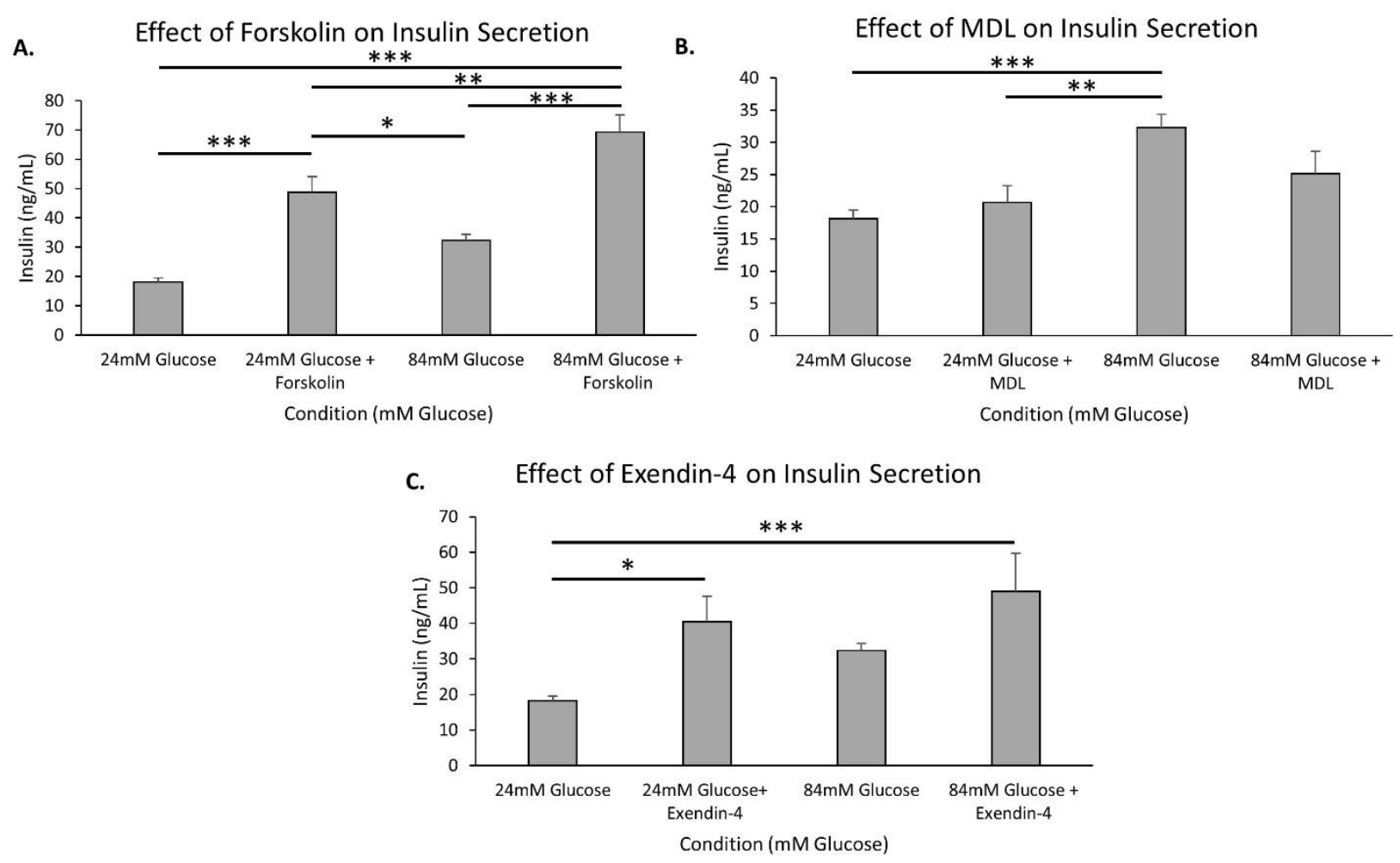

Figure 5. cAMP-related drug effect on insulin secretion in high glucose. (A-C) Murine islets were placed in wells containing modified KRB with $24 \mathrm{mM}$ or $84 \mathrm{mM}$ glucose \pm mannitol balanced to $84 \mathrm{mM}$ total for $1 \mathrm{~h}$ and then various drugs were added to each condition for $1 \mathrm{~h}$ of incubation before insulin was measured: $10 \mu \mathrm{M}$ forskolin (A), $10 \mu \mathrm{M}$ MDL 12,330A (B), and $10 \mathrm{nM}$ exendin-4 (C) All data are presented as \pm SEM. $\mathrm{N}=5-11$ replicates. ${ }^{*} p<0.05,{ }^{* *} p<0.01,{ }^{* * *} p<0.001$.

To examine the contribution of glycolytic activity leading to insulin secretion, the glucokinase activator R0-28-1675 (hereafter called GKA) was utilized, and insulin measurements were taken. As shown in Figure 4B, islets treated with GKA in $24 \mathrm{mM}$ glucose displayed a significant increase in insulin secretion compared to islets in $24 \mathrm{mM}$ alone $(p<0.01)$. Insulin secretion in $84 \mathrm{mM}$ glucose was on par with islets given GKA in $24 \mathrm{mM}$ glucose, but GKA did not provide any additional stimulation in $84 \mathrm{mM}$ glucose. Together, these data indicate that glycolytically driven insulin secretion continues to dose-dependently increase, nearly doubling insulin secretion between 24 and $84 \mathrm{mM}$ glucose.

\subsection{The cAMP Pathway Provides Additional Capacity for Insulin Secretion in Extremely High Glucose}

cAMP, a known amplifier of insulin secretion, was examined by the use of forskolin, an adenylyl cyclase activator that increases cAMP levels. As shown in Figure 5A, in $24 \mathrm{mM}$ glucose for $1 \mathrm{~h}$, forskolin increased insulin secretion dramatically compared to the control $24 \mathrm{mM}$ glucose $(p<0.001)$. There was also a significant difference found between $84 \mathrm{mM}$ glucose and $84 \mathrm{mM}$ glucose combined with forskolin $(p<0.001)$. In addition, the amount of insulin secreted at $84 \mathrm{mM}$ glucose with forskolin was significantly higher than the amount of insulin secreted at $24 \mathrm{mM}$ glucose with forskolin $(p<0.01)$. Overall, the cAMP pathway has the capacity to dramatically increase insulin secretion, even at extreme glucose concentrations.

MDL-12,330A (MDL), an adenylyl cyclase inhibitor, was used to determine if reducing cAMP by inhibiting adenylyl cyclase could block the additional insulin secretion in extreme hyperglycemic conditions. MDL appeared to partially inhibit insulin secretion in $84 \mathrm{mM}$ glucose. The significantly higher levels of insulin secretion in $84 \mathrm{mM}$ glucose compared to $24 \mathrm{mM}$ glucose were not significant with MDL added to $84 \mathrm{mM}$ glucose (Figure $5 \mathrm{~B}$ ). Importantly, MDL did not reduce insulin secretion in $24 \mathrm{mM}$ glucose compared to $24 \mathrm{mM}$ 
glucose alone, indicating that the inhibitory effects of MDL on adenylyl cyclase occur only in extremely high glucose conditions when adenylyl cyclase is likely contributing more to overall insulin secretion.

Pancreatic islets were next stimulated with exendin-4, a GLP-1 agonist, to examine the possible contributions of incretin pathways on insulin secretion in extreme glucose conditions. There was a significant increase in insulin secretion with exendin added to $24 \mathrm{mM}$ glucose compared to $24 \mathrm{mM}$ glucose alone $(p<0.05)$. However, when exendin was tested with $84 \mathrm{mM}$ glucose, there was no significant difference between $84 \mathrm{mM}$ glucose and $84 \mathrm{mM}$ glucose with exendin (Figure 5C). This indicates that insulin secretion, due to incretin effects, continues to increase between $24 \mathrm{mM}$ and $84 \mathrm{mM}$ glucose, revealing possible incretin involvement in the amplification pathway at extreme glucose concentrations.

\section{Discussion}

3.1. Maximum Glucose Concentrations for Glucose-Stimulated Insulin Secretion Are Much Higher Than Previously Reported

Our study demonstrates a surprisingly high capacity of islets to maintain stimulussecretion coupling in glucose concentrations far exceeding what is considered normal for both mice and humans. We showed that insulin secretion doubled from $24 \mathrm{mM}$ to $84 \mathrm{mM}$ glucose, while calcium levels were unchanged over the same range. This suggests that insulin secretion occurs through the amplifying pathway, which can contribute $50 \%$ or more to insulin secretion when calcium is saturated [22]. In addition, our findings suggest that there is still much to be learned about the mechanisms and limits of the amplifying pathway of glucose-stimulated insulin secretion.

\subsection{High Glucose Leads to Increased cAMP via Different Potential Mechanisms}

Insulin secretion stimulated by cAMP can be thought of in two independent routes, the secretion that is dependent on calcium changes and that which is stimulated from cellular glucose metabolism [16]. Once cAMP accumulates, intracellular calcium rises through increased L-type-calcium-channel activity $[23,24]$ and through release from intracellular stores [25]. Although cAMP thus has the capacity to increase intracellular calcium, our results reveal that intracellular calcium is already saturated in $24 \mathrm{mM}$ glucose, so any additional stimulation of insulin secretion would likely not involve changes in calciumdependent pathways. This study demonstrates that extremely high glucose levels can increase insulin secretion independently of the triggering pathway.

It is understood that increased glucose leads to an increase in cAMP [26]. Our data show that glucose continues to dose-dependently increase rates of glycolysis, as shown by a near doubling of insulin secretion between 24 and $84 \mathrm{mM}$ glucose. As shown in Figure 6, the effects of extreme glucose can be reproduced with GKA in $24 \mathrm{mM}$ glucose. This indicates that glycolytically driven metabolite formation is responsible for a large portion of insulin secreted above $24 \mathrm{mM}$ glucose. Additionally, it should be noted that in Figure 6, forskolin and MDL act directly on adenylyl cyclase to alter cAMP levels. Forskolin, which acts to increase adenylyl cyclase, showed a huge potential for stimulating insulin secretion at high glucose concentrations. With that, MDL was able to partially block the insulin released in extremely high glucose conditions. MDL may not have fully reduced the insulin secreted in $84 \mathrm{mM}$ glucose back down to $24 \mathrm{mM}$ levels as expected, since other pathways independent of cAMP are likely working synergistically to amplify insulin secretion. Regardless, there are several ways in which increased glucose metabolism can augment insulin secretion through cAMP that do not require changes in intracellular calcium. 


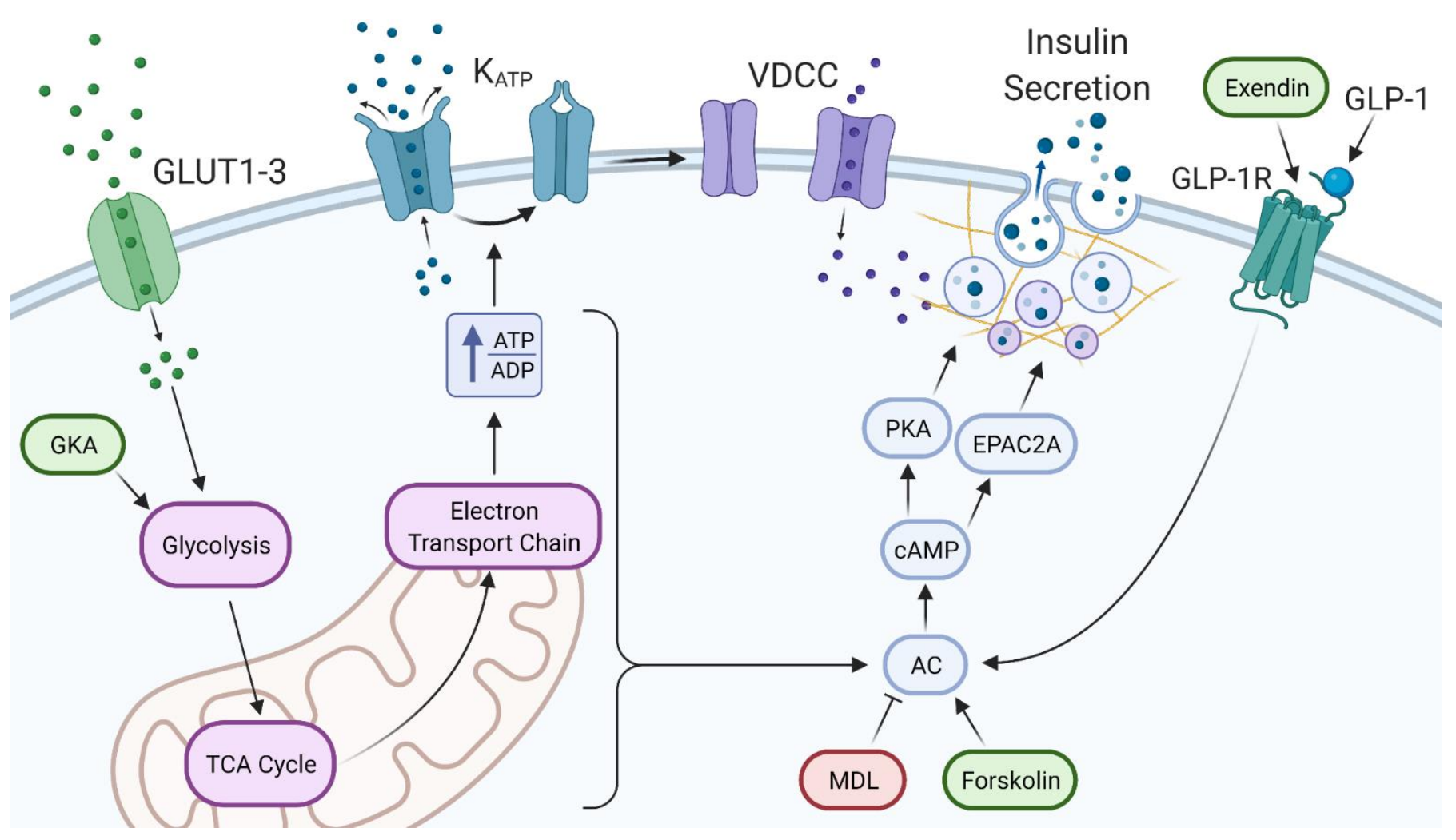

Figure 6. The triggering and amplifying pathways of insulin secretion in extreme glucose. (Left) Glucose enters the beta cell and is metabolized, causing an increase in the ATP to ADP ratio. ATP-sensitive potassium channels (KATP) close, causing membrane depolarization, the opening of voltage-dependent calcium channels (VDCC), and insulin secretion. (Right) GLP-1 from alpha cells or exendin stimulate beta-cell GLP-1 receptors which stimulate AC. Additionally, various metabolites produced from glucose metabolism can stimulate AC. Increased production of cAMP stimulates PKA and EPAC2A, causing increased insulin secretion by various mechanisms. Ovals indicate points of stimulation (green) or inhibition (red) for pharmacological agents used in these studies.

Protein kinase A (PKA) has a permissive role in increasing insulin secretion that has been shown to be glucose dependent [26]. This should be no surprise, since cAMP/PKA pathways have been long explored as targets for potential diabetes therapy [27]. As shown in Figure 6, cAMP activates downstream effectors PKA and guanine-nucleotide exchange protein (EPAC), which both lead to cAMP-mediated insulin secretion [28]. Focusing on the PKA pathway, glutamate derived from glucose through the malate aspartate shuttle is the specific signal underlying insulin secretion after being stimulated via cAMP [12]. It has been shown that the CAMP/PKA pathway potentiates the release of insulin via increased effectiveness of $K_{A T P}$-channel-independent actions of glucose [29], which is consistent with our observations. Intracellular calcium is unaffected by PKA activation, and PKA effects on insulin secretion are mediated by the phosphorylation of various downstream proteins [30]. The mechanisms leading to the rise in insulin secretion are studied with electrophysiological and optical methods which monitor the movements and exocytosis of individual insulin granules [31,32]. Changes in the size of distinct granular pools, facilitation of granule recruitment from the pools to the plasma membrane, and the acceleration of the priming process that confers granules with release competence may all play a role as well as the involvement of SNARE complexes. Relating this back to our study, the PKA pathway stemming from the increase in cAMP ties to the amplification pathway via glucose metabolism and is most likely a key player in insulin release at such high glucose concentrations.

In addition to what we have shown, there are other glucose-associated shunts that lead to insulin secretion through the amplification pathway. Our data suggest that glycolysis 
itself maintains glucose dependence well above $24 \mathrm{mM}$ glucose. Although, other than direct intermediates of glucose metabolism, there are potential excess-fuel detoxification pathways dealing with glycerol and free fatty acid formation and their extracellular release [32]. Free fatty acids play a role in insulin secretion by stimulating monoacylglycerol formation, whereas the inhibition of monoacylglycerol lipase activity decreases insulin secretion [33]. The aforementioned pathways may include the diversion of glucose carbons to triglycerides and cholesterol esters. Aspects relating to mitochondrial energy metabolism independent signals, including 1-monoglycerol, diacylglycerol, and malonyl-CoA are pieces of the amplification pathway to explore at high glucose levels. [33]. Future studies should investigate glycerol release and free fatty acids in extreme glucose conditions to further understand these intricate pathways.

\subsection{Paracrine Effects of Extreme Glucose via Alpha Cells}

Increasing glucose levels have been shown to lead to the induction of cAMP oscillations in both alpha and beta cells [34]. The alpha cells in pancreatic islets secrete GLP-1, which generally suppresses glucagon secretion [35]. Glucose-related glucagon secretion is observed in islets and reflects direct effects on alpha cells [29,30]. L-arginine can potently stimulate GLP-1 release in islets, and there is evidence that glucose may potentiate L-arginine-stimulated insulin secretion via PKA [36]. The relationship between glucose and GLP-1R is pivotal to understanding how glucose leads to an increase in cAMP.

It is known that glucose inhibits glucagon secretion by lowering cytoplasmic calcium in the alpha-cell; however, stimulation of glucagon at high glucose concentrations does not require an increase in intracellular calcium, and at higher glucose, glucagon secretion is actually stimulated. This paradoxical stimulation of glucagon release occurs around at least $25-30 \mathrm{mM}[30,31]$. In fact, high glucose has been shown to have a stimulatory effect on glucagon secretion possibly exceeding that of the inhibitory influence [37-39]. Looking at Figure 6, our studies demonstrate the connection of increasing glucose concentrations to increased GLP-1 and increased glucagon secreted by alpha cells. Our study suggests that the increase in incretins and glucagon from the alpha cells at high glucose concentrations could act on the beta cell to augment insulin secretion through the GLP-1 receptor pathway at these extreme levels.

\subsection{Clinical Relevance}

Diabetic patients have survived extreme glucose levels of over $100 \mathrm{mM}[2,4,10]$. Our study shows that insulin secretion occurs at extreme glucose levels, but as the concentration of glucose in the blood increases, insulin secretion in the higher glucose range does not keep to the same rate as in lower glucose concentrations, which is evidenced by the decrease in slope (Figure 1). However, this ability of beta cells to secrete insulin in these extremes of hyperglycemia is what distinguishes hyperosmolar hyperglycemic nonketoic syndrome from diabetic ketoacidosis. There is enough insulin present to prevent ketosis but not sufficient insulin to stimulate glucose utilization in target tissues $(\sim 10 \times$ as much insulin needed) [40]. We also observed that the extreme osmolarity increase associated with extreme hyperglycemia does not appear to negatively impact insulin secretion, at least in our in vitro studies in mouse islets. Thus, although individuals have survived, their bodies endured extreme stress during these instances. It should be noted that glucotoxicity has an effect on limiting the body's ability to secrete insulin in extreme conditions, but this is considered a more chronic state than what we report.

Overall, we showed that insulin secretion from islets of both mice and human donors continues to increase in a dose-dependent manner to much higher glucose levels than previously thought. It is possible that novel pathways to insulin secretion could be identified only by stimulation in extremely high glucose. Once identified, it may be possible to develop novel therapeutics that could stimulate this secretory activity without requiring extremely high glucose. 


\subsection{Strengths and Limitations}

An important strength of this study was the consistent observation in both murine and human islets in multiple trials which showed that the dose-dependent range of glucosestimulated insulin secretion extends far higher than commonly thought. We further show that these increases rely on increases in glycolytic activity and cAMP, but not on changes in intracellular calcium. In addition, these studies show that osmolarity does not impact insulin secretion in vitro, which eliminates a potential confounding variable. Limitations in this study include the fact that isolated islets in vitro lack normal neural and humoral inputs found in vivo that can modulate function. Islets also lack the vasculature of their in vivo environment, which can impact how nutrients like glucose reach the islet. These are issues common to any in vitro study of pancreatic islets. Lastly, although our study shows an important role for cAMP in the insulin response to extreme glucose, many other factors of the amplification pathway could also be involved. Examining additional mechanisms will be the focus of future work.

\section{Materials and Methods}

\subsection{Islet Sources and Isolation}

Mouse islets were isolated from male CD-1 (Envigo, Indianapolis, IN, USA) mice ages 8-12 weeks, as previously described [41]. Briefly, pancreatic islets were isolated using collagenase- $p$ digestion (Roche Diagnostics, Indianapolis, IN, USA) followed by centrifugation using Histopaque 1100 (Sigma-Aldrich, St. Louis, MO, USA). Islets were allowed to recover overnight in RPMI 1640 (Invitrogen, Carlsbad, CA, USA), supplemented with 10\% fetal bovine serum and $1 \%$ penicillin/streptomycin before being used for experiments. All animal procedures were approved by the Ohio University Institutional Animal Care and Use Committee. Human islets from deidentified donors were obtained from the University of Alberta IsletCore and the University of Alberta/Alberta Health Services Clinical Islet Laboratory.

\subsection{Calcium Imaging}

Fura-2 AM fluorescence imaging was utilized to measure intracellular calcium levels. Perifused solutions first passed through an inline heater to a temperature of $35+/-3$ degrees Celsius into an open diamond bath imaging chamber (Warner Instruments, Cat: 64-0288) which was mounted using a stage adapter (Warner Instruments, Cat: 64-0298). Observation of islets was performed using a Hamamatsu ORCA-Flash4.0 digital camera (Hamamatsu Photonics K.K., Hamamatsu City, Japan, Model C11440-22CU) mounted on a BX51WIF fluorescence microscope with a 10X objective (Olympus, Tokyo, Japan). Excitation light was provided by a xenon burner supplied to the image field through a light pipe and filter wheel (Sutter Instrument Co., Novato, CA, USA, Model LB-LS/30) with a Lambda 10-3 Optical Controller (Sutter Instrument Co., Novato, CA, USA, Model LB103-1572). Images were taken sequentially with $340 \mathrm{~nm}$ and $380 \mathrm{~nm}$ excitation to produce each ratio from emitted light at $510 \mathrm{~nm}$. Data were analyzed using cellSens Dimension 1.13 imaging software (Olympus, Tokyo, Japan) [42].

Islets were exposed to KRB containing $1 \mu \mathrm{M}$ fura-2 $\mathrm{AM}$ and incubated for $30 \mathrm{~min}$. They then were transferred onto the calcium scope. The fura- 2 signal was recorded for two different experimental protocols. Protocol 1: $3 \mathrm{mM}$ glucose $(\mathrm{G})$ for $5 \mathrm{~min}, 24 \mathrm{G}$ for $15 \mathrm{~min}$, and $84 \mathrm{G}$ for $15 \mathrm{~min}$. Protocol 2: $3 \mathrm{mM}$ glucose (G) for $5 \mathrm{~min}, 24 \mathrm{G}$ for $15 \mathrm{~min}, 24 \mathrm{G}$ containing $250 \mu \mathrm{M}$ tolbutamide for $15 \mathrm{~min}$, and back to $3 \mathrm{G}$ for $25 \mathrm{~min}$.

\subsection{Insulin Secretion}

To study insulin secretion, glucose-stimulated insulin secretion (GSIS) assays were performed. All GSIS used 12-well plates with 20 islets per well in $1 \mathrm{~mL}$ of KRB solution. Islets were size matched to aid in normalization as discussed in [43]. Briefly, islets were placed in $0 \mathrm{mM}$ glucose for one hour, then transferred to the experimental conditions for an additional hour. Supernatants were collected from experimental conditions of 0 , 
$12,24,36,48,60,72,84$, and $144 \mathrm{mM}$. Using the same approach, we studied additional conditions using osmolarity-matched solutions at $\sim 425 \mathrm{mOsm}$. Osmolarity was measured with Wescor Vapor Pressure Osmometer (Model 5520). Specific stimulators or inhibitors were placed into $24 \mathrm{G}$ and $84 \mathrm{G}$ to examine effects of exendin (10 nM, Sigma Aldrich, St. Louis, MO, USA, [18]), forskolin (10 $\mu \mathrm{M}$, Sigma Aldrich, St. Louis, MO, USA, [44]), MDL-12330A (10 M, Sigma Aldrich, St. Louis, MO, USA, [45]), and Ro-28-1675 (500 nM, Axon Medchem (Reston, VA, USA)). Insulin secretion was measured using mouse (Cat\#80INSMSU-E10) and human (Cat\#80-INSHU-E01.1) ELISA following the manufacturer's directions (ALPCO, Salem, NH, USA). Intra-assay variability was kept to below 15\% for all studies. D-mannitol (Sigma-Aldrich, St. Louis, MO, USA) was used to balance the osmolarity of Modified KRB solutions to $\sim 425 \mathrm{mOsm}$.

\subsection{Cell Death Quantification}

Islets were incubated in a glucose solution for $48 \mathrm{~h}$ in standard RPMI media supplemented $10 \%$ fetal bovine serum and $1 \%$ penicillin/streptomycin. Twenty islets were placed in each well per treatment in a 12-well plate. The 12-well plate contained the following treatments. Standard RPMI media, RPMI media+144 mM mannitol, RPMI media+60 mM glucose $+84 \mathrm{mM}$ mannitol, and finally RPMI+144 mM glucose. Cell death was measured with propidium iodide (Sigma-Aldrich, St. Louis, MO, USA) and annexin V (Invitrogen, Carlsbad, CA, USA) staining. Apoptosis was measured using annexin V (488 nm excitation/525 nm emission), which detects phosphatidylserine when it is exposed to the outer leaflet of the plasma membrane during apoptosis [46]. Propidium iodide (535 nm excitation/620 nm emission), which is a cell exclusion dye, was used to detect generalized cell death. Regions of interest were drawn around islets to measure fluorescence intensity per islet for each individual islet normalized to surface area. These techniques have been used in previous publications $[47,48]$ including in comparison to other methods to measure cell death [49].

\subsection{Statistical Analysis}

Statistical analysis was performed using R Statistical Computing Software. Data are expressed as the mean \pm standard error of the mean. Data were tested for normality using Shapiro-Wilk test and for equal variance using Levene's test. Henze-Zirkler's multivariate normality test was used for the insulin correlation data. All comparisons were analyzed using two-tailed $t$-test for comparisons of two groups or one-way ANOVA with Tukey's post hoc test for more than two groups. Differences between groups were considered significant at $p<0.05$. Spearman's rank correlation coefficient was used to analyze insulin secretion patterns in Figure 1.

\subsection{Ethical Approval}

All animal procedures were approved by the Ohio University Institutional Animal Care and Use Committee. Human islet isolation was approved by the Human Research Ethics Board at the University of Alberta (Pro00013094). All donors' families gave informed consent for the use of pancreatic tissue in research. Donor information was deidentified prior to our acquisition.

Author Contributions: Conceptualization, C.S.N., D.R.R., K.L.C., K.M.G.; methodology, all authors; software, N.B.W., C.S.N.; validation, all authors; formal analysis, K.M.G., C.S.N., N.B.W.; investigation, K.M.G., C.S.N., N.B.W., W.J.K.; resources, K.M.G., C.S.N.; data curation, K.M.G., C.S.N., N.B.W.; writing-original draft preparation, K.M.G., N.B.W.; writing-review and editing, C.S.N., K.M.G., N.B.W.; visualization, K.M.G., N.B.W., C.S.N.; supervision, C.S.N.; project administration, C.S.N.; funding acquisition, C.S.N. All authors have read and agreed to the published version of the manuscript.

Funding: This research was funded by NIDDK R15 DK121247, the Diabetes Institute, and the Ohio University Heritage College of Osteopathic Medicine. 
Institutional Review Board Statement: All animal procedures were approved by the Ohio University Institutional Animal Care and Use Committee. Human islet isolation was approved by the Human Research Ethics Board at the University of Alberta (Pro00013094 and Pro00001620). All donors' families gave informed consent for the use of pancreatic tissue in research. Donor information was deidentified prior to our acquisition.

Informed Consent Statement: All donors' families gave informed consent for the use of pancreatic tissue in research.

Data Availability Statement: All data used to support the findings of this study are available from the corresponding author upon request.

Acknowledgments: Human islets were provided by the Alberta Islet Distribution Program and by the Alberta Diabetes Institute IsletCore, University of Alberta in Edmonton. Islet isolation was approved by the Human Research Ethics Board at the University of Alberta (Pro00013094). The graphical abstract and Figure 6 were made using BioRender.

Conflicts of Interest: The authors declare no conflict of interest.

\section{References}

1. Komatsu, M.; Takei, M.; Ishii, H.; Sato, Y. Glucose-stimulated insulin secretion: A newer perspective. J. Diabetes Investig. 2013, 4, 511-516. [CrossRef] [PubMed]

2. Gupta, A.; Rohrscheib, M.; Tzamaloukas, A.H. Extreme hyperglycemia with ketoacidosis and hyperkalemia in a patient on chronic hemodialysis. Hemodial. Int. 2008, 12, S43-S47. [CrossRef]

3. Kharroubi, A.T.; Darwish, H.M. Diabetes mellitus: The epidemic of the century. World J. Diabetes 2015, 6, 850-867. [CrossRef] [PubMed]

4. Ahlsson, F.; Gedeborg, R.; Hesselager, G.; Tuvemo, T.; Enblad, P. Treatment of extreme hyperglycemia monitored with intracerebral microdialysis. Pediatr. Crit. Care Med. 2004, 5, 89-92. [CrossRef] [PubMed]

5. Alcazar, O.; Buchwald, P. Concentration-Dependency and Time Profile of Insulin Secretion: Dynamic Perifusion Studies with Human and Murine Islets. Front. Endocrinol 2019, 10, 680. [CrossRef]

6. Druet, C.; Tubiana-Rufi, N.; Chevenne, D.; Rigal, O.; Polak, M.; Levy-Marchal, C. Characterization of Insulin Secretion and Resistance in Type 2 Diabetes of Adolescents. J. Clin. Endocrinol. Metab. 2006, 91, 401-404. [CrossRef]

7. Johnson, D.; Shepherd, R.M.; Gill, D.; Gorman, T.; Smith, D.M.; Dunne, M.J. Glucose-dependent modulation of insulin secretion and intracellular calcium ions by GKA50, a glucokinase activator. Diabetes 2007, 56, 1694-1702. [CrossRef] [PubMed]

8. Ramachandran, K.; Peng, X.; Bokvist, K.; Stehno-Bittel, L. Assessment of re-aggregated human pancreatic islets for secondary drug screening. Br. J. Pharmacol. 2014, 171, 3010-3022. [CrossRef] [PubMed]

9. Lewandowski, S.L.; Cardone, R.L.; Foster, H.R.; Ho, T.; Potapenko, E.; Poudel, C.; VanDeusen, H.R.; Sdao, S.M.; Alves, T.C.; Zhao, X.; et al. Pyruvate Kinase Controls Signal Strength in the Insulin Secretory Pathway. Cell Metab. 2020, 32, 736-750. [CrossRef]

10. Gopalakrishnan, M.; Manappallil, R.G.; Ramdas, D.; Jayaraj, J. The survival story of a diabetic ketoacidosis patient with blood sugar levels of $1985 \mathrm{mg} / \mathrm{dL}$. Asian J. Med Sci. 2017, 8, 60. [CrossRef]

11. Highest Blood Sugar Level. Guinness World Records. Available online: https://www.guinnessworldrecords.com/worldrecords/highest-blood-sugar-level/ (accessed on 27 March 2020).

12. Gheni, G.; Ogura, M.; Iwasaki, M.; Yokoi, N.; Minami, K.; Nakayama, Y.; Harada, K.; Hastoy, B.; Wu, X.; Takahashi, H.; et al. Glutamate Acts as a Key Signal Linking Glucose Metabolism to Incretin/cAMP Action to Amplify Insulin Secretion. Cell Rep. 2014, 9, 661-673. [CrossRef]

13. Henquin, J.C. Triggering and amplifying pathways of regulation of insulin secretion by glucose. Diabetes 2000, 49, 1751-1760. [CrossRef] [PubMed]

14. Kalwat, M.A.; Cobb, M.H. Mechanisms of the amplifying pathway of insulin secretion in the $\beta$ cell. Pharmacol. Ther. 2017, 179, 17-30. [CrossRef]

15. Rustenbeck, I.; Schulze, T.; Morsi, M.; Alshafei, M.; Panten, U. What Is the Metabolic Amplification of Insulin Secretion and Is It (Still) Relevant? Metabolites 2021, 11, 355. [CrossRef]

16. Tengholm, A. Cyclic AMP dynamics in the pancreatic $\beta$-cell. Upsala J. Med. Sci. 2012, 117, 355-369. [CrossRef]

17. Evans-Molina, C.; Mirmira, R.G. Achieving 'PeaK-A' Insulin Secretion. Diabetes 2013, 62, 1389-1390. [CrossRef]

18. Peyot, M.-L.; Gray, J.P.; Lamontagne, J.; Smith, P.J.; Holz, G.G.; Madiraju, S.M.; Prentki, M.; Heart, E. Glucagon-like peptide-1 induced signaling and insulin secretion do not drive fuel and energy metabolism in primary rodent pancreatic $\beta$-cells. PLoS ONE 2009, 4, e6221. [CrossRef]

19. Tenny, S.; Patel, R.; Thorell, W. Mannitolin. In StatPearls; StatPearls Publishing: Treasure Island, FL, USA, 2021. Available online: http:/ / www.ncbi.nlm.nih.gov/books/NBK470392/ (accessed on 11 May 2021).

20. Lee, B.; Jonas, J.C.; Weir, G.C.; Laychock, S.G. Glucose regulates expression of inositol 1,4,5-trisphosphate receptor isoforms in isolated rat pancreatic islets. Endocrinology 1999, 140, 2173-2182. [CrossRef] [PubMed] 
21. Jonkers, F.C.; Guiot, Y.; Rahier, J.; Henquin, J.-C. Tolbutamide stimulation of pancreatic $\beta$-cells involves both cell recruitment and increase in the individual $\mathrm{Ca}^{2+}$ response. Br. J. Pharmacol. 2001, 133, 575-585. [CrossRef] [PubMed]

22. Henquin, J.C. Regulation of insulin secretion: A matter of phase control and amplitude modulation. Diabetologia 2009, 52, 739. [CrossRef] [PubMed]

23. Henquin, J.C.; Meissner, H.P. The ionic, electrical, and secretory effects of endogenous cyclic adenosine monophosphate in mouse pancreatic B cells: Studies with forskolin. Endocrinology 1984, 115, 1125-1134. [CrossRef] [PubMed]

24. Yada, T.; Itoh, K.; Nakata, M. Glucagon-like peptide-1-(7-36)amide and a rise in cyclic adenosine $3^{\prime}, 5^{\prime}$-monophosphate increase cytosolic free $\mathrm{Ca}^{2+}$ in rat pancreatic beta-cells by enhancing $\mathrm{Ca}^{2+}$ channel activity. Endocrinology 1993, 133, 1685-1692. [CrossRef]

25. Liu, Y.J.; Grapengiesser, E.; Gylfe, E.; Hellman, B. Crosstalk between the cAMP and inositol trisphosphate-signalling pathways in pancreatic beta-cells. Arch. Biochem. Biophys. 1996, 334, 295-302. [CrossRef]

26. Chepurny, O.G.; Kelley, G.G.; Dzhura, I.; Leech, C.A.; Roe, M.W.; Dzhura, E.; Li, X.; Schwede, F.; Genieser, H.G.; Holz, G.G. PKA-dependent potentiation of glucose-stimulated insulin secretion by Epac activator 8-pCPT-2'-O-Me-cAMP-AM in human islets of Langerhans. Am. J. Physiol. Endocrinol. Metab. 2009, 298, E622-E633. [CrossRef]

27. Yang, H.; Yang, L. Targeting cAMP/PKA pathway for glycemic control and type 2 diabetes therapy. J. Mol. Endocrinol. 2016, 57, R93-R108. [CrossRef]

28. Seino, S.; Shibasaki, T. PKA-dependent and PKA-independent pathways for cAMP-regulated exocytosis. Physiol. Rev. 2005, 85, 1303-1342. [CrossRef]

29. Yajima, H.; Komatsu, M.; Schermerhorn, T.; Aizawa, T.; Kaneko, T.; Nagai, M.; Sharp, G.W.; Hashizume, K. cAMP enhances insulin secretion by an action on the ATP-sensitive $\mathrm{K}+$ channel-independent pathway of glucose signaling in rat pancreatic islets. Diabetes 1999, 48, 1006-1012. [CrossRef] [PubMed]

30. Kaihara, K.A.; Dickson, L.M.; Jacobson, D.A.; Tamarina, N.; Roe, M.W.; Philipson, L.H.; Wicksteed, B. $\beta$-Cell-Specific Protein Kinase A Activation Enhances the Efficiency of Glucose Control by Increasing Acute-Phase Insulin Secretion. Diabetes 2013, 62, 1527-1536. [CrossRef] [PubMed]

31. Gaisano, H.Y. Here come the newcomer granules, better late than never. Trends Endocrinol. Metab. 2014, 25, 381-388. [CrossRef] [PubMed]

32. Henquin, J.-C.; Nenquin, M. Activators of PKA and Epac Distinctly Influence Insulin Secretion and Cytosolic Ca ${ }^{2+}$ in Female Mouse Islets Stimulated by Glucose and Tolbutamide. Endocrinology 2014, 155, 3274-3287. [CrossRef]

33. Lamontagne, J.; Al-Mass, A.; Nolan, C.J.; Corkey, B.E.; Madiraju, S.M.; Joly, E.; Prentki, M. Identification of the signals for glucose-induced insulin secretion in INS1 $(832 / 13) \beta$-cells using metformin-induced metabolic deceleration as a model. J. Biol. Chem. 2017, 292, 19458-19468. [CrossRef] [PubMed]

34. Tian, G.; Sandler, S.; Gylfe, E.; Tengholm, A. Glucose- and hormone-induced cAMP oscillations in $\alpha$ - and $\beta$-cells within intact pancreatic islets. Diabetes 2011, 60, 1535-1543. [CrossRef] [PubMed]

35. Liu, P.; Song, J.; Liu, H.; Yan, F.; He, T.; Wang, L.; Shen, H.; Hou, X.; Chen, L. Insulin regulates glucagon-like peptide-1 secretion by pancreatic alpha cells. Endocrine 2018, 62, 394-403. [CrossRef]

36. Thams, P.; Capito, K. L-arginine stimulation of glucose-induced insulin secretion through membrane depolarization and independent of nitric oxide. Eur. J. Endocrinol. 1999, 140, 87-93. [CrossRef]

37. Salehi, A.; Vieira, E.; Gylfe, E. Paradoxical stimulation of glucagon secretion by high glucose concentrations. Diabetes 2006, 55, 2318-2323. [CrossRef] [PubMed]

38. Yu, Q.; Shuai, H.; Ahooghalandari, P.; Gylfe, E.; Tengholm, A. Glucose controls glucagon secretion by directly modulating cAMP in alpha cells. Diabetologia 2019, 62, 1212-1224. [CrossRef] [PubMed]

39. Gylfe, E.; Gilon, P. Glucose regulation of glucagon secretion. Diabetes Res. Clin. Pract. 2014, 103, 1-10. [CrossRef] [PubMed]

40. Gosmanov, A.R.; Gosmanova, E.O.; Kitabchi, A.E. Hyperglycemic Crises: Diabetic Ketoacidosis (DKA), and Hyperglycemic Hyperosmolar State (HHS). In Endotext; Feingold, K.R., Anawalt, B., Boyce, A., Chrousos, G., de Herder, W.W., Dhatariya, K., Dungan, K., Grossman, A., Hershman, J.M., Hofland, J., et al., Eds.; MDText.com, Inc.: South Dartmouth, MA, USA, 2000. Available online: http:/ / www.ncbi.nlm.nih.gov/books/NBK279052/ (accessed on 25 May 2021).

41. Corbin, K.L.; West, H.L.; Brodsky, S.; Whitticar, N.B.; Koch, W.J.; Nunemaker, C.S. A Practical Guide to Rodent Islet Isolation and Assessment Revisited. Biol. Proced. Online 2021, 23, 7. [CrossRef]

42. Whitticar, N.B.; Strahler, E.W.; Rajan, P.; Kaya, S.; Nunemaker, C.S. An Automated Perifusion System for Modifying Cell Culture Conditions over Time. Biol. Proced. Online 2016, 18, 19. [CrossRef]

43. Slepchenko, K.G.; Corbin, K.L.; Nunemaker, C.S. Comparing methods to normalize insulin secretion shows the process may not be needed. J. Endocrinol. 2019, 241, 149-159. [CrossRef] [PubMed]

44. Ammon, H.P.T.; Muller, A.B. Effect of forskolin on islet cyclic AMP, insulin secretion, blood glucose and intravenous glucose tolerance in rats. Naunyn-Schmiedeberg's Arch. Pharmacol. 1984, 326, 364-367. [CrossRef]

45. Li, X.; Guo, Q.; Gao, J.; Yang, J.; Zhang, W.; Liang, Y.; Wu, D.; Liu, Y.; Weng, J.; Li, Q.; et al. The Adenylyl Cyclase Inhibitor MDL-12,330A Potentiates Insulin Secretion via Blockade of Voltage-Dependent K+ Channels in Pancreatic Beta Cells. PLoS ONE 2013, 8, e77934. [CrossRef] [PubMed]

46. Baskić, D.; Popović, S.; Ristić, P.; Arsenijević, N.N. Analysis of cycloheximide-induced apoptosis in human leukocytes: Fluorescence microscopy using annexin V/propidium iodide versus acridin orange/ethidium bromide. Cell Biol. Int. 2006, 30, 924-932. [CrossRef] 
47. Dula, S.B.; Jecmenica, M.; Wu, R.; Jahanshahi, P.; Verrilli, G.M.; Carter, J.D.; Brayman, K.L.; Nunemaker, C.S. Evidence that low-grade systemic inflammation can induce islet dysfunction as measured by impaired calcium handling. Cell Calcium 2010, 48, 133-142. [CrossRef] [PubMed]

48. Gelin, L.; Li, J.; Corbin, K.L.; Jahan, I.; Nunemaker, C.S. Metformin Inhibits Mouse Islet Insulin Secretion and Alters Intracellular Calcium in a Concentration-Dependent and Duration-Dependent Manner near the Circulating Range. J. Diabetes Res. 2018, 2018, 9163052. [CrossRef] [PubMed]

49. O’Neill, C.M.; Lu, C.; Corbin, K.L.; Sharma, P.R.; Dula, S.B.; Carter, J.D.; Ramadan, J.W.; Xin, W.; Lee, J.K.; Nunemaker, C.S. Circulating Levels of IL-1B+IL-6 Cause ER Stress and Dysfunction in Islets from Prediabetic Male Mice. Endocrinology 2013, 154, 3077-3088. [CrossRef] 